\title{
Atypical Implant Failure
}

\author{
L Massa $^{1}$ and JA von Fraunhofer ${ }^{2 *}$ \\ ${ }^{1}$ Boerne Dentist, Premier Dental Center, USA \\ ${ }^{2}$ School of Dentistry, University of Maryland, USA
}

Received: 監 January 19, 2018; Published: 眥January 25, 2018

*Corresponding author: JA von Fraunhofer, School of Dentistry, University of Maryland, USA

\begin{abstract}
With an average survival rate of $95 \%$, the endosseous dental implant is one of the most successful and predictable innovations in modern dentistry. The factors contributing to the success, and failure, of dental implants are now well-established [1-6] and include the oral and systemic health of the patient, patient age, implant type, implant surface, implant length, bone type, surgical site (mandible or maxilla), type of surgery (one- or two-stage) and immediate (fresh socket) or delayed implant placement. Other important aspects regarding the success of an implant include the skill, experience and, apparently gender, of the surgeon [7]. Early implant failures, a prevalence of about $5.6 \%$, most often is observed in edentulous upper jaws, notably with implants having a turned surface. There is some controversy as to whether pre- and post-operative antibiotic coverage is needed, but overall antibiotic therapy can be helpful but apparently is only essential when infection is present.
\end{abstract}

\section{Clinical}

A healthy, well-nourished 76 year old man without systemic or oral diseases presented with missing teeth in tooth positions \#18 and \#19. The patient previously had successful implant surgery together with a sinus lift in the maxilla some years prior to the present surgery. The patient had no history of metal allergies and satisfied the selection criteria for successful implant surgery. Pre-operative radiographs, Figure 1, showed that the bone at the surgical site was compact and well-vascularized. The satisfactory bone conditions at the implant sites were confirmed by CT scan. After fabrication of a placement template for the implants, sockets for the implants was prepared using the Nobel Biocare tapered osteotomy drill kit, utilizing the $2 \mathrm{~mm}$ twist drill, the $3.5 \mathrm{~mm}$ drill, the $4.3 \mathrm{~mm}$ drill and the $4.3 \mathrm{~mm}$ dense bone drill.

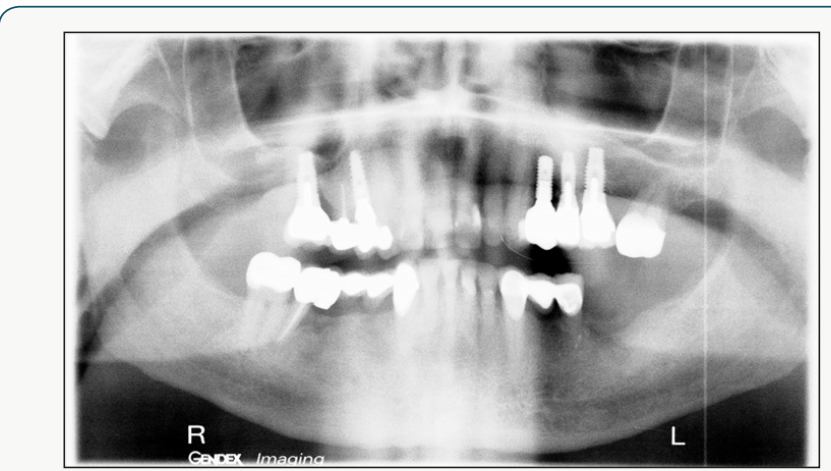

Figure 1: Pre-operative Panorex of the patient oral cavity.
The placed implants were Nobel Biocare tapered conical implants, $4.3 \mathrm{~mm}$ diameter $\mathrm{x} 10 \mathrm{~mm}$ length. The implants were placed by the same surgeon in positions 18 and 19, Figure 2. No antibiotic coverage was deemed necessary because there was no evidence of infection at the surgical site. Four months after implant placement, the implant at tooth \#18 started to extrude, Figure 3, followed by complete loss of the implant within 5 days. Follow-up radiographs and clinical examination showed no indications of infection at the implant site, Figure 4. There was no indication of epithelial down growth surrounding the implant at any time, and no soft tissue residue was noted on the revered implant.

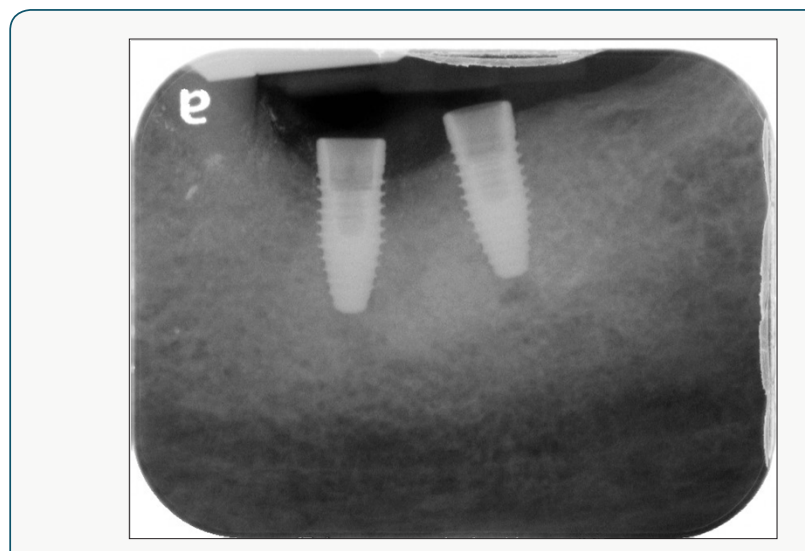

Figure 2: Post-operative radiographs of placed implants. 

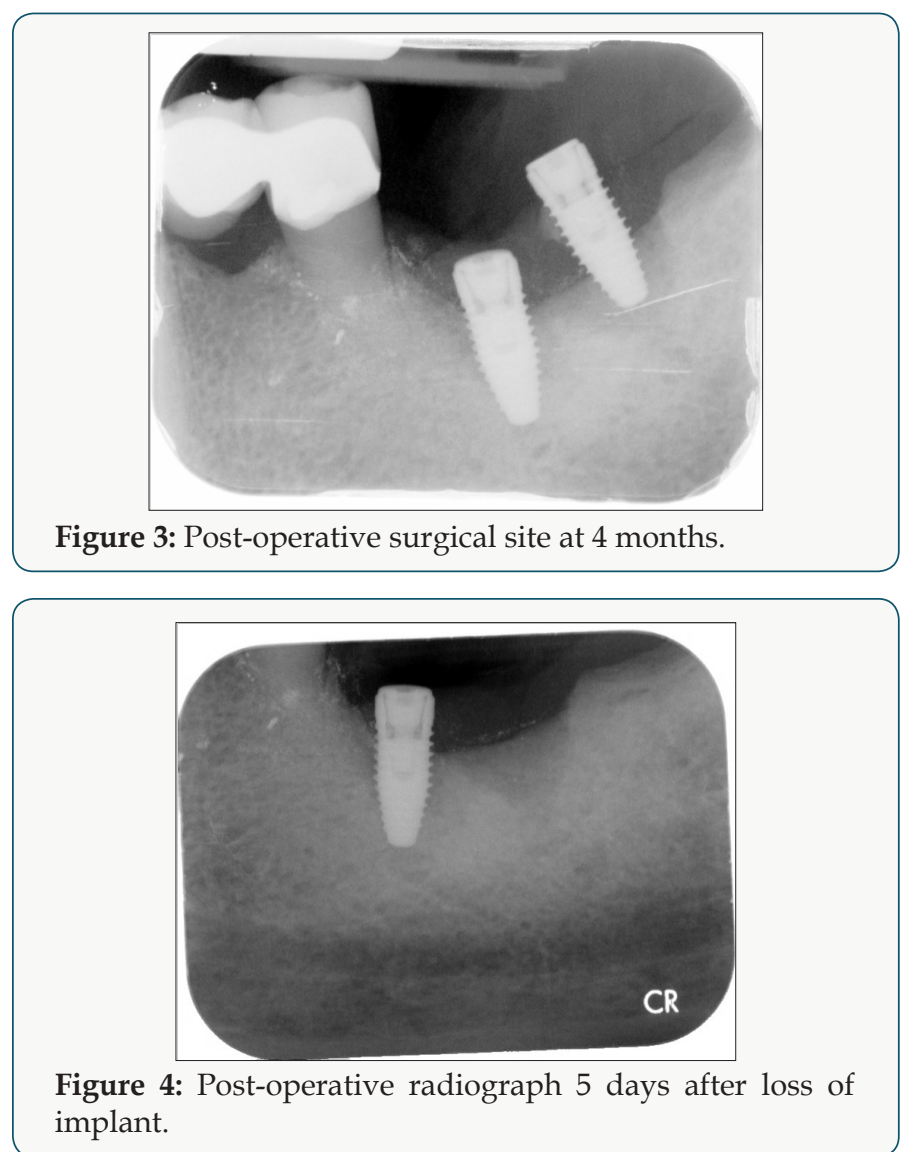

\section{Discussion}

This implant failure appears to have no simple explanation. Implant failure within 6 months of placement is uncommon, occurring in about $5 \%$ of all cases. However, many of the recognized factors contributing to early failure did not apply in the present case. Both implants were placed by the same very experienced male surgeon. Further, there were no signs of pre-operative or postoperative infection and the surgical site was in the mandible rather than the maxilla, the latter being the more common site for early implant failure [7]. Interestingly although recent research suggests that the administration of prophylactic antibiotics may significantly reduce the prevalence of dental implant failure under ordinary conditions but certainly when infection is present or might be anticipated. Neither situation was present in this particular case.

It is possible that the design of the implant might have contributed to failure although when an identical implant was placed in the bone adjacent to \#18, there appears to be satisfactory osseous integration. Overall, there appears to be no logical explanation for this individual implant failure since none of the potential contributory factors to early failure apply in this particular case. It is proposed that a different design of implant will be placed in 4-6 months' time after complete healing of the implant site. Prior to surgical site preparation and implant placement, the authors intend to closely monitor both patient and the mandible to ensure success of the next surgery.

\section{Conclusion}

Although the endosseous dental implant is one of the most successful and predictable innovations in modern dentistry and all factors contributing to the success of dental implants were satisfied in this particular case, failure still occurred. Operator skill and expertise were not in question in this case because the surgeon has placed over 2000 implants without incident over a period of years. The reason for failure is not clear and, certainly, implant \#19 was deemed to be successful. The final conclusion to be drawn is that implant failures can occur for inexplicable reasons and from no readily ascribable causes.

\section{References}

1. Porter JA, von Fraunhofer JA (2005) Success or failure of dental implants? A literature review with treatment considerations. General Dentistry 53(6): 423-432.

2. Griggs JA (2017) Dental Implants. Dental Clinics of North America 61(4): 857-871.

3. Oztel M, Bilski WM, Bilski A (2017) Risk Factors associated with Dental Implant Failure: A Study of 302 Implants placed in a Regional Center. The Journal of Contemporary Dental Practice 18(8): 705-709.

4. Mohajerani H, Roozbayani R, Taherian S, Tabrizi R (2017) The Risk Factors in Early Failure of Dental Implants: a retrospective study. Journal of Dentistry (Shiraz) 18(4): 298-303.

5. Carr AB, Revuru VS, Lohse CM (2017) Association of Systemic Conditions with Dental Implant Failures in 6,384 Patients During a 31-Year Followup Period. The International Journal of Oral Maxillofacial Implants 32(5): 1153-1161.

6. Chrcanovic BR, Kisch J, Albrektsson T, Wennerberg A (2017) Impact of Different Surgeons on Dental Implant Failure. The International Journal of Prosthodontics 30(5): 445-454.

7. Jemt T, Olsson M, Renouard F, Stenport V, Friberg B (2016) Early Implant Failures Related to Individual Surgeons: An Analysis Covering 11,074 Operations Performed During 28 Years. Clinical Implant Dentistry and Related Research 18(5): 861-872. 
(C) (D) This work is licensed under Creative

Submission Link: Submit Article

DOI: 10.32474/MADOHC.2018.01.000105

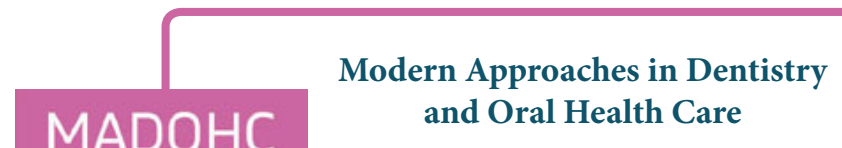

Assets of Publishing with us

- Global archiving of articles

- Immediate, unrestricted online access

- Rigorous Peer Review Process

- Authors Retain Copyrights

- Unique DOI for all articles 